\title{
Propensity-matched comparison of video-assisted thoracoscopic with thoracotomy lobectomy for locally advanced non-small cell lung cancer
}

\author{
Kezhong Chen, MD, Xun Wang, MD, Fan Yang, MD, Jianfeng Li, MD, Guanchao Jiang, MD,
} Jun Liu, MD, and Jun Wang, MD

\begin{abstract}
Objective: We evaluated whether video-assisted thoracoscopic lobectomy for locally advanced non-small cell lung cancer could be performed safely and with acceptable long-term outcomes by our improved technique and compared with standard thoracotomy lobectomy in a well-balanced population.

Methods: Patients with clinical stage II and III A non-small cell lung cancers who received lobectomy were reviewed. Video-assisted thoracoscopic lobectomies were all performed with Wang's technique by the surgeons who had overcome the learning curve and achieved proficiency. By using propensity-matched analysis, perioperative outcomes and long-term survival were compared.
\end{abstract}

Results: Matching based on propensity scores produced 120 patients in each group. Conversion rate to thoracotomy was $11.7 \%$. After thoracoscopic lobectomy, hospital length of stay was shorter compared with thoracotomy (9.2 vs 12 days; $P=.014)$ despite similar rates of postoperative complications $(30 / 125$ [25\%] vs 34/125 [28.3\%]; $P=.56)$. Disease-free survival $(49.1 \%$ vs $42.2 \%$; $P=.40)$ and overall survival $(55.0 \%$ vs $57.1 \% ; P=.73)$ at 5 years were similar between groups. Although advanced pathologic stage (hazard ratio [HR], 2.018; $95 \%$ confidence interval [CI], 1.330-3.062) and no postoperative chemotherapy (HR, 1.880; 95\% CI, 1.236-2.858) were independently associated with increased hazard of death in multivariable Cox regression at each time point in follow-up, thoracoscopic lobectomy was not (HR, 1.075; 95\% CI, 0.714-1.620; $P=.73$ ).

Conclusions: With continued experience and optimized technique, video-assisted thoracoscopic lobectomy can be performed in the majority of cases without compromising perioperative outcomes and oncologic efficacy. (J Thorac Cardiovasc Surg 2017;153:967-76)

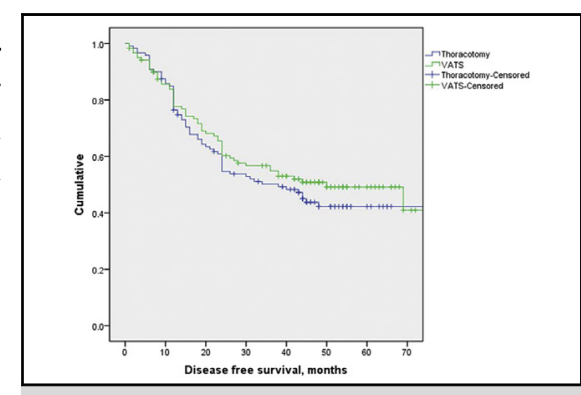

DFS between VATS and thoracotomy groups.

Central Message

With continued experience and optimized technique, VATS lobectomy can be performed without compromising perioperative outcomes and oncologic efficacy.

\section{Perspective}

This is the first well-balanced comparative study to adequately compare VATS with thoracotomy lobectomy for locally advanced NSCLC. All the VATS were conducted by thoracic surgeons who had achieved proficiency in the improved technique, which ensured VATS at a consistent level. VATS lobectomy can be performed safely with similar long-term survival compared with thoracotomy in non-stage I NSCLC.

See Editorial Commentary page 977
Growing evidence has suggested that video-assisted thoracoscopic surgery (VATS) lobectomy is a preferred approach for patients with early-stage non-small cell lung cancer (NSCLC) with superior short- and long-term outcomes. ${ }^{1,2}$ However, most previous studies for VATS in lung cancer were limited to early-stage disease in which the results of

\footnotetext{
From the Department of Thoracic Surgery, Peking University People's Hospital, Beijing, China.

This study was supported by the UICC Fellowship (ICR15-353370).

Received for publication Feb 18, 2016; revisions received Oct 29, 2016; accepted for publication Dec 5, 2016; available ahead of print Jan 11, 2017.

Address for reprints: Jun Wang, MD, Department of Thoracic Surgery, Peking University People's Hospital, Beijing 100044, China (E-mail: wangjun@pkuph. edu.cn).

$0022-5223 / \$ 36.00$

Copyright (c) 2016 by The American Association for Thoracic Surgery

http://dx.doi.org/10.1016/j.jtcvs.2016.12.008
}

VATS for patients with other disease stages were not clear. Some studies involved a mixture of stages, and results showed that VATS was not inferior to thoracotomy. ${ }^{3,4}$ However, because a majority of patients in these studies were stage I disease, the results of VATS for patients with other disease stages may have been overestimated. We cannot draw any conclusion regarding VATS and thoracotomy for those patients with non-stage I lung cancer.

Scanning this QR code will take you to supplemental figures and video for this article.

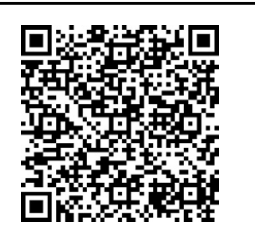




$$
\begin{aligned}
& \text { Abbreviations and Acronyms } \\
& \begin{aligned}
\text { CI } & =\text { confidence interval } \\
\text { CT } & =\text { computed tomography } \\
\text { DFS } & =\text { disease-free survival } \\
\text { HR } & =\text { hazard ratio } \\
\text { NSCLC } & =\text { non-small cell lung cancer } \\
\text { OS } & =\text { overall survival } \\
\text { VATS } & =\text { video-assisted thoracoscopic surgery }
\end{aligned}
\end{aligned}
$$

With the continuous development of surgical instruments, such as high-definition cameras and display devices (1080P), new-generation endoscopic staplers with rotating heads, and retraction instruments, technical difficulties for advanced cases have been gradually overcome. ${ }^{5}$ Thoracic surgeons with increasing experience have made VATS safer and have expanded the indications for thoracoscopic resection. Tumors once thought unapproachable by thoracoscopic techniques are now frequently resected by VATS.

Hennon and Demmy ${ }^{5}$ confirmed the safety of thoracoscopic lobectomy in locally advanced lung cancer. We have previously presented our thoracoscopic experience in patients with tumors larger than $5 \mathrm{~cm} .{ }^{6}$ However, because there have been no well-balanced comparative studies with sufficient evidence to adequately compare VATS lobectomy with thoracotomy lobectomy for locally advanced NSCLC, several concerns regarding completeness of oncologic resection, technical challenges, and potential safety have limited the use of minimally invasive techniques for more advanced stages of lung cancer. Therefore, we conducted this study to evaluate whether VATS lobectomy by our improved technique could be performed with acceptable short- and long-term outcomes when compared with standard thoracotomy for patients with locally advanced NSCLC in a wellbalanced large population from a multi-institutional database.

\section{MATERIALS AND METHODS \\ Patient Eligibility}

We reviewed our lung cancer surgery database, which was prospectively maintained and included a consecutive cohort of patients who underwent curative surgery of lung cancer in our institution and a series of other hospitals in China. This prospective multi-institutional database was established on the basis of 2 other prospective studies since 2010, which required that for patients enrolled in this database, each hospital had to adopt the same protocols for diagnosis and perioperative management. All of the patients underwent contrast-enhanced thoracic computed tomography $(\mathrm{CT})$ scans before surgery. Other routine preoperative examinations included chest radiograph, cardiopulmonary function tests, abdominal and adrenal gland ultrasonography or CT, brain magnetic resonance imaging or $\mathrm{CT}$, and a bone scan. If mediastinal lymph node enlargement was demonstrated on chest CT, endobronchial ultrasound transbronchial needle aspiration or mediastinoscopic biopsy was performed first. Positron emission tomography/CT was not mandatory in every patient.

The inclusion criterion of this study was patients who underwent a lobectomy for lung cancer with clinical locally advanced stage (stage IIa, IIb, or IIIa) by the 7th American Joint Committee on Cancer TNM staging system.
We reviewed the database from January 2010 to December 2012 and identified 524 patients from 7 high-level comprehensive cancer hospitals in China. Patients who underwent bilobectomy, pneumonectomy, or sleeved lobectomy were excluded. Patients who had small cell lung cancer or incomplete data were also excluded. In all, 411 patients were included, of whom 250 had a VATS lobectomy and 161 had a thoracotomy were identified. The hospital accumulated data with prospective patient permission on the scientific use of collected data, and the protocols of this study were approved by the Institutional Review Board of Peking University People's Hospital.

\section{Clinical Variables}

We collected clinical variables of patients, including age, gender, comorbidities, forced expiratory volume in 1 second, diffusing capacity for carbon monoxide, smoking history ( $<100$ cigarettes defined as nonsmokers), TNM stage, tumor histology, and tumor location and size measured by CT. Postoperative complications were described according to the Common Terminology Criteria for Adverse Events Version 3.0. A prolonged air leak was one that lasted more than 7 days postoperatively. All of the hospitals in our multi-institutional database adopted the same indication to remove the chest tube when the drainage was less than $200 \mathrm{~mL} / \mathrm{d}$ for 2 days.

Chest CT scan and abdominal ultrasound/CT are performed on follow-up visits every 6 months after operation for 5 years. Magnetic resonance imaging and bone scan are performed every year for 5 years or any time that the patient has symptoms. The overall survival (OS) was estimated from the date of surgical resection to death of any cause or the date of last follow-up. Disease-free survival (DFS) was defined as the time from the day of surgery until the first event (relapse, metastasis, or death from any cause) or last follow-up. Perioperative mortality was defined as death within 30 days of the operation.

\section{Operative Technique}

More than $90 \%$ of lobectomies were performed by VATS at Peking University People's Hospital. Because of the relatively higher morbidity of tuberculosis and infection, Chinese patients with lung cancer present with more severe adhesions between lymph nodes and blood vessels than patients in many other countries. ${ }^{7}$ This situation has caused us to develop more efficient and safer methods to undertake these difficult surgeries. Peking University People's Hospital is an experienced center; thus, we summarized and optimized our technique for the long-term minimally invasive thoracic surgical treatment for lung cancer, and we developed our improved technique (Wang's technique), which has been described. ${ }^{7,8}$ The major features of our technique are as follows (Video 1): (1) a specially made

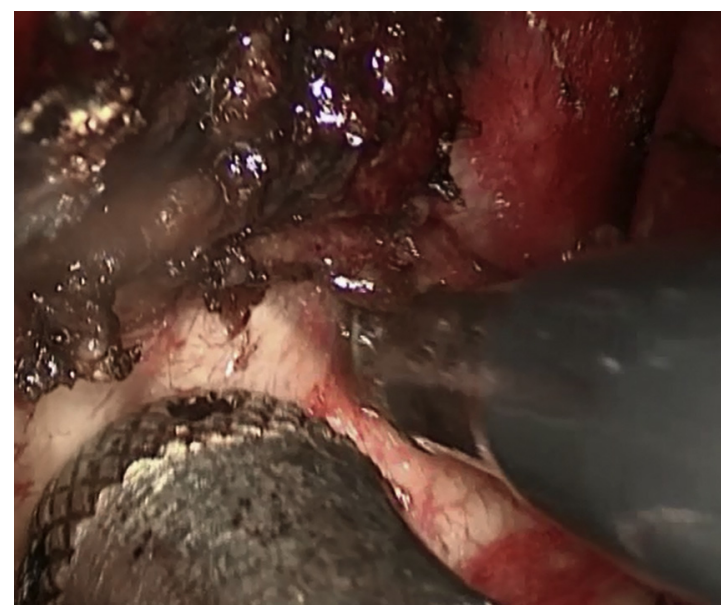

VIDEO 1. VATS right upper lobectomy by Wang's technique. Video available at: http://www.jtcvsonline.org/article/S0022-5223(16)31671-3/ addons. 
TABLE 1. Patient characteristics

\begin{tabular}{|c|c|c|c|}
\hline & VATS $(n=250)$ & Thoracotomy $(n=161)$ & $P$ value \\
\hline Age, $y \pm S D$ & $62.2 \pm 10.3$ & $60.2 \pm 9.6$ & .05 \\
\hline \multicolumn{4}{|l|}{ Sex, n $(\%)$} \\
\hline Male & $121(62.4)$ & $156(75.2)$ & .007 \\
\hline Tumor size, $\mathrm{cm} \pm \mathrm{SD}$ & $3.3 \pm 1.6$ & $4.8 \pm 2.2$ & $<.001$ \\
\hline FEV $1 \%$ & 78.2 & 79.6 & .14 \\
\hline $\mathrm{DLCO} \%$ & 82.6 & 81.1 & .25 \\
\hline \multicolumn{4}{|l|}{ Comorbidities, n (\%) } \\
\hline No comorbidities & $147(58.8)$ & $117(72.7)$ & .004 \\
\hline Diabetes mellitus & $24(9.6)$ & $11(6.8)$ & .33 \\
\hline Hypertension & $74(29.6)$ & $29(18)$ & .008 \\
\hline History of MI & $27(10.8)$ & $4(2.5)$ & .002 \\
\hline COPD & $8(60.8)$ & $6(3.7)$ & .77 \\
\hline Renal insufficiency & $11(4.4)$ & $5(3.1)$ & .51 \\
\hline Neoadjuvant, n (\%) & $6(2.4)$ & $11(6.8)$ & .028 \\
\hline Smoking history, $\mathrm{n}(\%)$ & $108(43.2)$ & $98(60.9)$ & $<.001$ \\
\hline cTNM, n (\%) & & & .065 \\
\hline IIA & $113(45.2)$ & $61(37.9)$ & \\
\hline IIB & $32(12.8)$ & $34(21.1)$ & \\
\hline IIIA & $105(42)$ & $66(41)$ & \\
\hline cT stage, n (\%) & & & .002 \\
\hline $\mathrm{T} 1$ & $60(24)$ & $26(16.1)$ & \\
\hline $\mathrm{T} 2$ & $159(63.6)$ & $94(58.4)$ & \\
\hline $\mathrm{T} 3$ & 29 (11.6) & $34(21.1)$ & \\
\hline $\mathrm{T} 4$ & $2(2.2)$ & $7(4.3)$ & \\
\hline cN stage, $\mathrm{n}(\%)$ & & & .87 \\
\hline No & $72(28.8)$ & $50(31.1)$ & \\
\hline N1 & $84(33.6)$ & $51(31.7)$ & \\
\hline $\mathrm{N} 2$ & $94(37.6)$ & $60(37.3)$ & \\
\hline Tumor location, n (\%) & & & .07 \\
\hline Right upper & $81(32.4)$ & $49(30.4)$ & \\
\hline Right middle & $18(7.2)$ & $4(2.5)$ & \\
\hline Right lower & $53(21.2)$ & $27(16.8)$ & \\
\hline Left upper & $65(26.0)$ & $49(30.4)$ & \\
\hline Left lower & $33(13.2)$ & $32(19.9)$ & \\
\hline
\end{tabular}

VATS, Video-assisted thoracoscopic surgery; $S D$, standard deviation; $F E V I$, forced expiratory volume in 1 second; $D L C O$, diffusing capacity for carbon monoxide; $M I$, myocardial infarction; $C O P D$, chronic obstructive pulmonary diseases.

2-curved suction and an electrocautery hook are handled concurrently through a single incision and double-crossed in the same direction. (2) A perivascular tunnel is created for interlobar fissure division. (3) Cutting off the bronchial artery is a priority. (4) Vessels are freed in their subadventitial plane. (5) The mediastinal pleura is unfolded around the hilum of the lung. All of the VATS lobectomies in this study were conducted by the thoracic surgeons who had overcome the learning curve and achieved proficiency of VATS lobectomy ( $>200$ lobectomies independently), which has been published..$^{9,10}$

Thoracoscopy was performed at the beginning of all operative procedures to assess the extent of disease. Conversions were defined as operations that began with thoracoscopic dissection and were concluded as a rib-spreading thoracotomy. Thoracoscopic evaluation without structural dissection that continued as an open case did not qualify as a conversion and was considered a planned thoracotomy. The patients who converted from VATS to thoracotomy were analyzed in the VATS cohort for the reason of "intent-to-treat" method. ${ }^{11}$ All of the thoracotomy lobectomies were performed via a standard posterolateral thoracotomy incision.

Systematic mediastinal lymph nodal dissection or sampling was mandatory. Lymph nodes in groups 2, 4, 7, and N1 were resected for the right-side lesion, and lymph nodes in groups 5, 6, 7, and N1 were resected for the leftside lesion.

\section{Statistical Analysis}

Univariate analysis of categoric data between VATS and thoracotomy groups was conducted using the Fisher exact test or Pearson's chi-square test. Student $t$ test or Mann-Whitney $U$ test was used to assess for 2group comparisons of continuous variables, which are expressed as the mean values and standard deviations. Propensity score matching was performed to balance the baseline of the patients by logistic regression model. VATS versus thoracotomy was the treatment indicator, and the variables were age, sex, each comorbidity, forced expiratory volume in 1 second, diffusing capacity for carbon monoxide, smoking history, clinical $\mathrm{T}$ stage, clinical $\mathrm{N}$ stage, clinical stage, neoadjuvant treatment, tumor size, and tumor location. VATS and thoracotomy pairs with a nearest propensity score were matched 1 to 1 with a caliper width of 0.2 of standard deviation (Figures E1 and E2). Postoperative outcomes from the matched cohorts were then compared. OS and DFS were evaluated by Kaplan-Meier survival analysis. Log-rank tests were used to determine the statistical significance of survival between the 2 groups. Univariable and multivariable analyses using the Cox proportional hazards models were constructed to 
TABLE 2. Propensity score-matched comparison of baseline characteristics between video-assisted thoracoscopic surgery and thoracotomy groups

\begin{tabular}{|c|c|c|c|c|}
\hline & $\operatorname{VATS}(\mathbf{n}=120)$ & Thoracotomy $(\mathbf{n}=\mathbf{1 2 0})$ & SD before & SD after \\
\hline Age, $y \pm S D$ & $60.3 \pm 10.2$ & $60.9 \pm 9.3$ & 0.196 & -0.075 \\
\hline \multicolumn{5}{|l|}{ Sex, n (\%) } \\
\hline Male & $81(67.5)$ & $86(71.7)$ & -0.263 & -0.086 \\
\hline Tumor size, $\mathrm{cm} \pm \mathrm{SD}$ & $3.8 \pm 1.8$ & $4.1 \pm 1.8$ & -0.991 & -0.127 \\
\hline FEV1\% & 79.0 & 79.2 & -0.166 & -0.023 \\
\hline $\mathrm{DLCO} \%$ & 81.3 & 80.9 & 0.105 & -0.051 \\
\hline \multicolumn{5}{|l|}{ Comorbidities, n (\%) } \\
\hline Diabetes mellitus & $10(8.3)$ & $9(7.5)$ & 0.094 & -0.056 \\
\hline Hypertension & $25(20.8)$ & $26(21.7)$ & 0.253 & 0.018 \\
\hline History of MI & $5(4.2)$ & $4(3.3)$ & 0.267 & 0.134 \\
\hline COPD & $4(3.3)$ & $5(4.2)$ & -0.030 & 0.047 \\
\hline Renal insufficiency & $5(4.2)$ & $5(4.2)$ & 0.063 & 0.000 \\
\hline Neoadjuvant, n (\%) & $4(3.2 \%)$ & $5(4 \%)$ & -0.289 & 0.000 \\
\hline Smoking history, n (\%) & $68(56.7)$ & $67(55.8 \%)$ & -0.356 & -0.084 \\
\hline cTNM, n (\%) & & & -0.067 & -0.009 \\
\hline IIA & $52(43.3 \%)$ & $52(43.3 \%)$ & & \\
\hline IIB & $24(20 \%)$ & $18(15 \%)$ & & \\
\hline IIIA & $44(36.7 \%)$ & $50(41.7 \%)$ & & \\
\hline cT stage, n (\%) & & & -0.398 & -0.068 \\
\hline $\mathrm{T} 1$ & $23(19.2)$ & $25(20.8)$ & & \\
\hline $\mathrm{T} 2$ & $81(67.5)$ & $75(62.5)$ & & \\
\hline $\mathrm{T} 3$ & $15(12.5)$ & $16(13.3)$ & & \\
\hline $\mathrm{T} 4$ & $1(0.8)$ & $4(3.3)$ & & \\
\hline cN stage, n (\%) & & & 0.032 & 0.010 \\
\hline No & $34(28.3)$ & $32(26.7)$ & & \\
\hline N1 & $42(35.0)$ & $40(33.0)$ & & \\
\hline $\mathrm{N} 2$ & $44(36.7)$ & $48(40.0)$ & & \\
\hline Tumor location, n (\%) & & & -0.181 & 0.063 \\
\hline Right upper & $35(29.2)$ & $40(33.3)$ & & \\
\hline Right middle & $3(2.5)$ & $3(2.5)$ & & \\
\hline Right lower & $33(27.5)$ & $19(15.8)$ & & \\
\hline Left upper & $35(29.2)$ & $39(32.5)$ & & \\
\hline Left lower & 14 (11.7) & $19(15.8)$ & & \\
\hline
\end{tabular}

Differences $<-0.25$ and $>0.25$ are significant (at least $P<.05$ ). VATS, Video-assisted thoracoscopic surgery; $S D$, standard deviation; FEVI, forced expiratory volume in 1 second; $D L C O$, diffusing capacity for carbon monoxide; $M I$, myocardial infarction; $C O P D$, chronic obstructive pulmonary disease.

assess the potential independent effects on DFS and OS. Predictors $(P<.2)$ in univariable analysis were incorporated into a multivariable analysis. We used PASW SPSS for Windows version 22.0 (IBM, Chicago, Ill) and R version 2.15.3 (R Foundation for Statistical Computing, Vienna, Austria) for statistical analysis.

\section{RESULTS}

The medical records of 411 patients with locally advanced NSCLC who underwent lobectomy were included, 250 patients underwent VATS, and 161 patients underwent thoracotomy. Patient characteristics are shown in Table 1.

\section{Perioperative Outcomes}

After propensity score matching, 120 patients from the thoracotomy group were matched and compared with 120 patients from the thoracoscopic group (Table 2). There was 1 perioperative death in each group and no intraoperative deaths. All patients were R0 resected. Fourteen patients $(11.7 \%)$ in the VATS group were converted to thoracotomy. Reasons for conversions were bleeding $(\mathrm{n}=2)$, large tumor size $(\mathrm{n}=2)$, lymph node calcification $(n=7)$, margins that needed to be extended $(n=1)$, and failed fissure dissociation $(\mathrm{n}=2)$.

Median surgery time, blood loss, and tube duration were not significantly different between the 2 groups. When the conversion group was placed in the thoracotomy group, the blood loss (141 vs $184 \mathrm{~mL}, P=.006$ ) was significantly less in the VATS group than in the thoracotomy group. A total of 37 adverse events occurred in 30 patients in the VATS group, and 45 adverse events occurred in the 34 patients undergoing thoracotomy. Thoracoscopic lobectomy was associated with a shorter length of hospital stay (9.2 vs 12 days, $P=.014$ ) (Table 3).

To evaluate the thoroughness of lymph node clearance by VATS or thoracotomy, both the mean number of lymph 
TABLE 3. Comparison of perioperative outcomes between video-assisted thoracoscopic surgery and thoracotomy groups

\begin{tabular}{|c|c|c|c|}
\hline & $\operatorname{VATS}(\mathbf{n}=120)$ & Thoracotomy $(n=120)$ & $P$ value* \\
\hline Surgery time, min, median (range) & $183(90-465)$ & $200(90-535)$ & .64 \\
\hline Blood loss, mL, median (range) & $147(20-1000)$ & $180(40-1100)$ & .06 \\
\hline Tube duration, d, median (range) & $6.6(2-24)$ & $7(3-16)$ & .94 \\
\hline LOS, d, median (range) & $9.2(4-35)$ & $12(4-26)$ & .014 \\
\hline \multicolumn{4}{|l|}{ Complication, $\mathrm{n}(\%)$} \\
\hline Any complication & $30(25)$ & $34(28.3)$ & .56 \\
\hline Prolonged air leak & $17(14.2)$ & $22(12.5)$ & .70 \\
\hline Bleeding & $2(1.7)$ & $2(1.7)$ & 1.0 \\
\hline Atelectasis & $2(1.7)$ & $2(1.7)$ & 1.0 \\
\hline Pneumonia & $2(1.7)$ & $3(2.5)$ & 1.0 \\
\hline Atrial arrhythmia & $5(4.2)$ & $8(6.7)$ & .39 \\
\hline Heart failure & $1(0.8)$ & $1(0.8)$ & 1.0 \\
\hline Chylothorax & $3(2.5)$ & $1(0.8)$ & .62 \\
\hline Wound infection & $2(1.7)$ & $4(3.3)$ & .68 \\
\hline Others & $3(2.5)$ & $2(1.7)$ & 1.0 \\
\hline Histology, n (\%) & & & .19 \\
\hline Adenocarcinoma & $84(70)$ & $72(60)$ & \\
\hline Squamous carcinoma & $34(28.3)$ & $47(39.2)$ & \\
\hline Others & $2(1.7)$ & $1(0.8)$ & \\
\hline pStage, n (\%) & & & .95 \\
\hline IA & $3(2.5)$ & $3(2.5)$ & \\
\hline IB & $6(5.0)$ & $7(5.8)$ & \\
\hline IIA & $44(36.7)$ & $43(35.8)$ & \\
\hline IIB & $16(13.3)$ & $16(13.3)$ & \\
\hline IIIA & $48(40.0)$ & $50(41.7)$ & \\
\hline IIIB & $3(2.5)$ & $1(0.8)$ & \\
\hline \multicolumn{4}{|l|}{ Lymph nodes, mean $\pm \mathrm{SD}$} \\
\hline Total stations & $5.5 \pm 1.8$ & $5.5 \pm 1.6$ & .85 \\
\hline Total lymph nodes & $15.6 \pm 9.2$ & $14.7 \pm 7.9$ & .42 \\
\hline N1 stations & $2.2 \pm 0.9$ & $2.0 \pm 0.8$ & .09 \\
\hline N1 lymph nodes & $5.3 \pm 4.0$ & $5.3 \pm 3.7$ & .96 \\
\hline $\mathrm{N} 2$ stations & $3.3 \pm 1.2$ & $3.5 \pm 1.4$ & .17 \\
\hline N2 lymph nodes & $10.3 \pm 7.0$ & $9.4 \pm 5.8$ & .27 \\
\hline
\end{tabular}

VATS, Video-assisted thoracoscopic surgery; $L O S$, length of hospital stay; $S D$, standard deviation. * $P$ values are based on Mann-Whitney $U$ tests for abnormal distributed continuous data.

nodes and nodal stations removed were compared between the 2 groups. There were no differences in the number and stations of N1, N2, or total lymph nodes between the 2 surgical approaches. When we separated our patients into 2 groups according to the operation time, similar to Lee and colleagues' recent study, ${ }^{12}$ our data also showed an increase in nodal harvest by VATS as time progressed. In the early group (January 2010 to June 2011), no differences were found between VATS and thoracotomy, except that more total nodal stations (5.8 vs 5.2, $P=.037$ ) and N2 stations ( 3.7 vs $3.3, P=.046$ ) were resected by thoracotomy than VATS. Compared with the early group, a greater number of total nodal stations (5.8 vs $5.1 P=.046$ ), lymph nodes (16.5 vs $12.2 P=.011)$, N1 stations (2.4 vs 1.8 , $P<.001$ ), N1 lymph nodes (5.7 vs $4.3, P=.048$ ), and N2 lymph nodes (10.8 vs $8.0, P=.042)$ were retrieved by VATS than thoracotomy in the late group (July 2011 to December 2012).
Because most of the patients in this study had stage II or III disease, adjuvant chemotherapy was recommended. The chemotherapy regimens administered in the 2 groups were similar, which included gemcitabine, pemetrexed, docetaxel plus cisplatin, or paclitaxel plus carboplatin every 3 weeks. It seemed that more patients in the VATS group could tolerate all 4 (or more) cycles at the fully planned dose on schedule, but this difference was not significant (Table 4).

\section{Oncologic Efficacy}

The last follow-up was completed in January 2016. The median follow-up period was 45 months (range, 1-72). The location of recurrence was not significantly different between the 2 groups (Table 5). Three-year DFS was $50.1 \%$ in the open thoracotomy group and $54.8 \%$ in the VATS group. Five-year DFS was $42.2 \%$ in the open thoracotomy group and $49.1 \%$ in the VATS group. There was no 
TABLE 4. Chemotherapy compliance after lobectomy by different approaches

\begin{tabular}{lccc}
\hline & VATS $(\mathbf{n}=\mathbf{1 2 0})$ & Thoracotomy $(\mathbf{n}=\mathbf{1 2 0})$ & $\boldsymbol{P}$ value \\
\hline Adjuvant chemotherapy, $\mathrm{n}(\%)$ & $84(70.0)$ & $78(65.0)$ & .41 \\
Receive full dose on schedule, $\mathrm{n}(\%)$ & $62(51.7)$ & $51(42.5)$ & .16 \\
Time to start chemotherapy, d, mean \pm SD & $33.9 \pm 3.0$ & $34.5 \pm 3.4$ & .21 \\
Cycles completed, mean \pm SD & $2.4 \pm 1.8$ & $2.2 \pm 2.0$ & .33 \\
\hline
\end{tabular}

VATS, Video-assisted thoracoscopic surgery; $S D$, standard deviation.

significant difference in recurrence between the 2 groups $(P=.40)$ (Figure $1, A)$. The overall 3-year survival was $72.6 \%$ in the thoracotomy group and $78.2 \%$ in the VATS group. The overall 5-year survival was $57.1 \%$ in the thoracotomy group and $55 \%$ in the VATS group. There was no significant difference in survival between the 2 groups $(P=.73)$ (Figure 1, $B)$. When the conversions were placed in the thoracotomy group, the VATS group seemed to have a better 5-year DFS (51.7\% vs $40.7 \%, P=.124)$ (Figure 2, $A$ ) and OS $(57.9 \%$ vs $54.5 \%, P=.182)$ (Figure $2, B)$ according to the curves, but there was no significant difference. By comparing the clinical stages, there was no difference between the VATS group and thoracotomy group in 5-year DFS (stage IIa, $50 \%$ vs $53 \%, P=.988$; stage IIb, $51.8 \%$ vs $40 \%, P=.814$; stage IIIa, $44.2 \%$ vs $30 \%$, $P=.386$ ) and OS (stage IIa, $56.4 \%$ vs $66.8 \%, P=.606$; stage IIb, $62 \%$ vs $72.2 \%, P=.914$; stage IIIa, $48.4 \%$ vs $41.4 \%, P=.291)$.

Multivariable Cox regression analysis of DFS and OS showed that 2 independent predictors were pathologic stage and adjuvant chemotherapy, whether the conversions were placed in the VATS group or thoracotomy group. The worse DFS (hazard ratio [HR], 2.365; 95\% confidence interval $[\mathrm{CI}], 1.618-3.458 ; P<.001)$ and OS (HR, 2.018; 95\% CI, $1.330-3.062 ; P=.001)$ occurred in patients with advanced pathologic stage and patients without adjuvant chemotherapy (DFS, HR, 1.609; 95\% CI, 1.094-2.366; $P=.016) \quad(\mathrm{OS}, \mathrm{HR}, 1.880 ; 95 \%$ CI, 1.236-2.858; $P=.003)$ (Tables 6 and 7).

\section{DISCUSSION}

Although thoracoscopic resection for advanced-stage NSCLC has been reported, ${ }^{13}$ few studies have been designed specifically to validate the potential benefits of VATS for advanced lung cancer. We attempted to be as objective as possible in comparing the 2 approaches. First, our study benefitted from a multi-institutional prospective data collection that was reviewed every week by the attending surgical staff, which should have been more accurate than acquisition of retrospective data. Second, our VATS technique has been described, ${ }^{7,8}$ and all VATS were conducted by thoracic surgeons who had achieved proficiency $(>200$ lobectomies $)$ in this improved technique (Wang's technique). ${ }^{10}$ Most previous studies comparing VATS and thoracotomy did not show all surgeons being proficient in the surgery. ${ }^{14}$ As a traditional surgery, the thoracotomy lobectomy techniques were almost the same and were conducted with consistent standard posterolateral thoracotomies in different hospitals. Therefore, we could minimize bias by the skills of the surgeons and equally compare the 2 approaches.

After matching, our cohort of patients were well balanced in all categories between the thoracotomy and VATS lobectomy groups, which minimized bias from known confounders. Cao and colleagues ${ }^{4}$ performed a large matched study of VATS versus thoracotomy; however, the study lacked detailed data, perioperative outcomes, oncologic efficacy, and DFS were not compared. Therefore, we consider our study the first well-balanced comparative study to

TABLE 5. Summary of recurrence patterns between the 2 groups

\begin{tabular}{|c|c|c|c|c|}
\hline & All patients $(n=240)$ & $\operatorname{VATS}(\mathbf{n}=120)$ & Thoracotomy $(\mathbf{n}=120)$ & $P$ value \\
\hline Overall recurrence & 123 & 58 & 65 & 87 \\
\hline Locoregional, n (\%) & 51 & $24(41.4)$ & $27(41.5)$ & \\
\hline Ipsilateral lung & 31 & 13 & 18 & \\
\hline Lymph node & 20 & 11 & 9 & \\
\hline Distant, n (\%) & 57 & $26(44.8)$ & $31(47.7)$ & \\
\hline Contralateral lung & 5 & 3 & 2 & \\
\hline Brain & 19 & 10 & 9 & \\
\hline Bone & 20 & 7 & 13 & \\
\hline Liver & 6 & 2 & 4 & \\
\hline Others & 7 & 4 & 3 & \\
\hline Local and distant, n (\%) & 15 & $8(13.8)$ & $7(10.8)$ & \\
\hline
\end{tabular}

VATS, Video-assisted thoracoscopic surgery. 

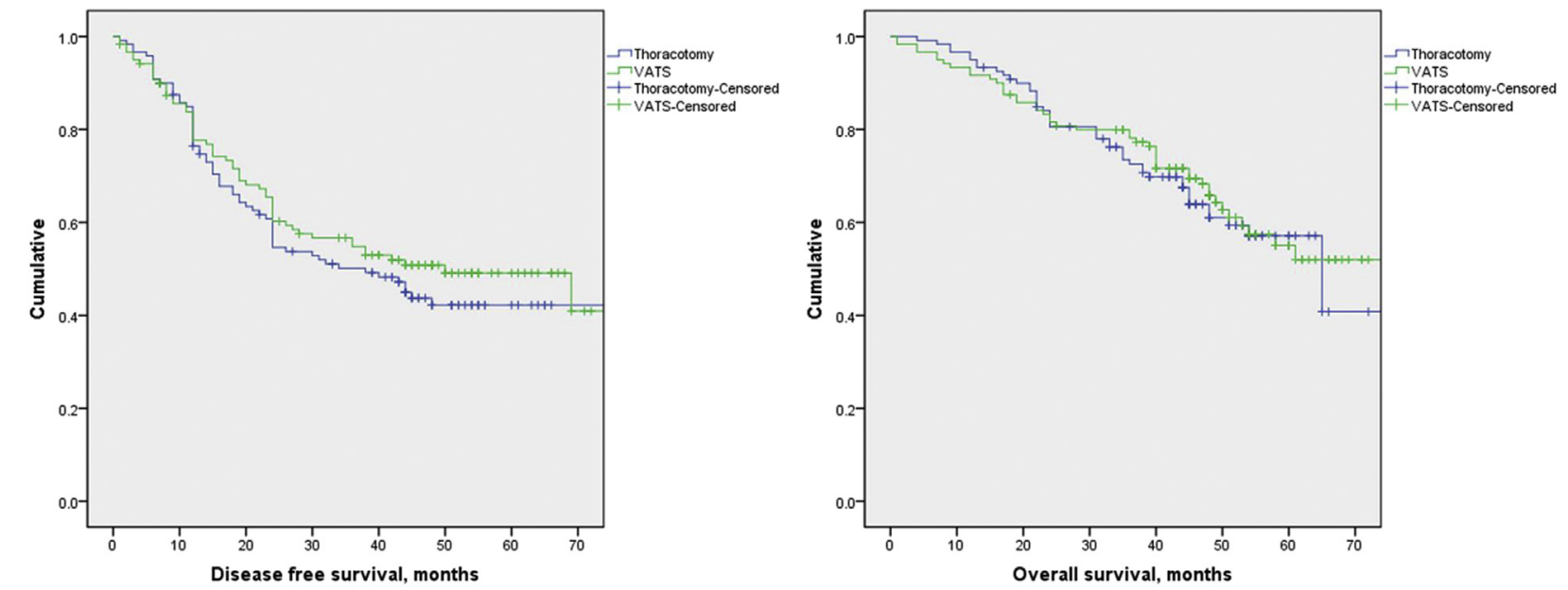

Number at risk

$\begin{array}{llllllll}\text { VATS } 120 & 98 & 78 & 63 & 52 & 27 & 14 & 4 \\ \text { Open } 120 & 111 & 73 & 59 & 50 & 25 & 8 & 2\end{array}$

DFS(3 \& 5year)

$\begin{array}{llll}\text { A Open } & 54.8 \%, 95 \% \mathrm{Cl}(50.1-59.5) & 49.1 \%, 95 \% \mathrm{Cl}(44.2-54.0) \\ & 50.1 \%, 95 \% \mathrm{Cl}(45.4-54.8) & 42.2 \%, 95 \% \mathrm{Cl}(37.4-47.0)\end{array}$
Number at risk

$\begin{array}{llllllll}\text { VATS } 120 & 112 & 102 & 94 & 74 & 38 & 18 & 6 \\ \text { Open } 120 & 116 & 106 & 93 & 72 & 38 & 10 & 3\end{array}$

OS(3 \& 5year)

VATS $\quad 79.9 \%, 95 \% \mathrm{Cl}(76.2-83.6) \quad 55.0 \%, 95 \% \mathrm{Cl}(49.4-60.6)$ $72.6 \%, 95 \% \mathrm{Cl}(68.5-76.7) \quad 57.1 \%, 95 \% \mathrm{Cl}(51.8-62.4)$

FIGURE 1. A, DFS between thoracotomy and VATS groups $(P=.40)$. B, OS between thoracotomy and VATS groups $(P=.73)$. VATS, Video-assisted thoracoscopic surgery; $D F S$, disease-free survival; $C I$, confidence interval; $O S$, overall survival.

adequately compare VATS lobectomy with thoracotomy lobectomy for locally advanced NSCLC. In recent clinical guidelines such as the American College of Chest Physicians, we could only conclude that "For patients with clinical stage I NSCLC, a minimally invasive approach such as video-assisted thoracic surgery is preferred over a thoracotomy..." ${ }^{11}$ Our study provides evidence comparing VATS and thoracotomy for non-stage I NSCLC.

In the current study, the conversion rate from VATS to thoracotomy was not greater than published VATS
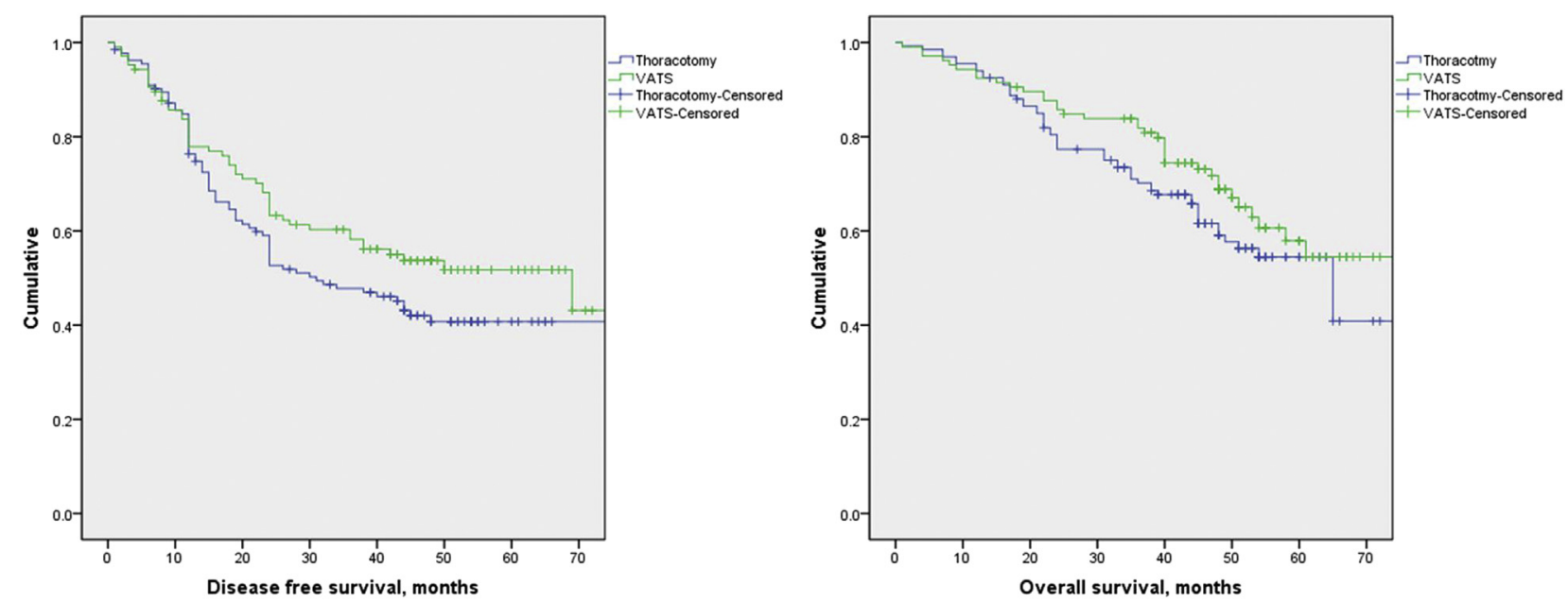

Number at risk

$\begin{array}{llllllll}\text { VATS } 106 & 88 & 73 & 60 & 49 & 24 & 14 & 4 \\ \text { Open } 134 & 111 & 78 & 62 & 53 & 28 & 8 & 2\end{array}$

DFS(3 \& 5year)

$\begin{array}{lll}\text { A OATS } & 58.2 \%, 95 \% \mathrm{Cl}(53.3-63.1) & 51.7 \%, 95 \% \mathrm{Cl}(46.5-56.9) \\ & 47.8 \%, 95 \% \mathrm{Cl}(43.4-52.2) & 40.7 \%, 95 \% \mathrm{Cl}(36.2-45.2)\end{array}$

\begin{tabular}{|c|c|c|c|c|c|c|c|c|}
\hline \multicolumn{9}{|c|}{ Number at risk } \\
\hline & VATS 106 & 100 & 94 & 87 & 67 & 34 & 17 & 5 \\
\hline & Open 134 & 128 & 114 & 100 & 79 & 42 & 11 & 4 \\
\hline \multicolumn{9}{|c|}{ OS(3 \& 5year) } \\
\hline \multirow[b]{2}{*}{$\mathbf{B}$} & VATS & \multicolumn{4}{|c|}{$79.8 \%, 95 \% \mathrm{Cl}(75.9-83.7)$} & \multicolumn{3}{|c|}{$57.9 \%, 95 \% \mathrm{Cl}(51.8-64.0)$} \\
\hline & Open & & $70.2 \%, 9$ & $5 \% \mathrm{Cl}(6$ & $5.2-74.2)$ & & $4.5 \%$ & $\% \mathrm{Cl}(49.5-59.5)$ \\
\hline
\end{tabular}

FIGURE 2. A, DFS between thoracotomy and VATS groups (conversions in the thoracotomy group) $(P=.12)$. B, OS between thoracotomy and VATS groups (conversions in the thoracotomy group) $(P=.18)$. VATS, Video-assisted thoracoscopic surgery; $D F S$, disease-free survival; $C I$, confidence interval; $O S$, overall survival. 
TABLE 6. Univariable and multivariable Cox analyses for disease-free survival

\begin{tabular}{|c|c|c|c|c|}
\hline & \multicolumn{2}{|c|}{ Univariable analysis } & \multicolumn{2}{|c|}{ Multivariable analysis } \\
\hline & HR $(95 \%$ CI $)$ & $P$ value & HR $(95 \%$ CI $)$ & $P$ value \\
\hline Age & $0.985(0.968-1.003)$ & .097 & $0.988(0.972-1.004)$ & .150 \\
\hline \multicolumn{5}{|l|}{ Sex } \\
\hline Female/male & $1.204(0.828-1.753)$ & .33 & & \\
\hline Tumor size & $0.964(0.872-1.066)$ & .47 & & \\
\hline \multicolumn{5}{|l|}{ Smoking history } \\
\hline No/yes & $1.414(0.993-2.015)$ & .055 & $1.244(0.851-1.820)$ & .26 \\
\hline \multicolumn{5}{|l|}{ Comobility } \\
\hline No/yes & $1.136(0.772-1.670)$ & .52 & & \\
\hline \multicolumn{5}{|l|}{ Histology } \\
\hline Nonadenocarcinoma/adenocarcinoma & $0.779(0.53-1.146)$ & .21 & & \\
\hline FEV $1 \%$ & $0.990(0.973-1.007)$ & .24 & & \\
\hline $\mathrm{DLCO} \%$ & $0.987(0.974-1.000)$ & .058 & $0.987(0.973-1.001)$ & .063 \\
\hline \multicolumn{5}{|l|}{ Location } \\
\hline Left/right lobe & $0.775(0.541-1.111)$ & .17 & $0.834(0.569-1.222)$ & .35 \\
\hline Middle or lower/upper lobe & $0.741(0.509-1.078)$ & .12 & $0.693(0.466-1.033)$ & .072 \\
\hline \multicolumn{5}{|l|}{ Lymph node dissection } \\
\hline Stations & $0.956(0.865-1.056)$ & .38 & & \\
\hline Number & $0.989(0.966-1.013)$ & .39 & & \\
\hline N1 stations & $0.867(0.710-1.058)$ & .16 & $0.953(0.740-1.228)$ & .71 \\
\hline N1 number & $0.958(0.908-0.011)$ & .12 & $0.968(0.903-1.038)$ & .36 \\
\hline $\mathrm{N} 2$ stations & $0.978(0.857-1.115)$ & .74 & & \\
\hline N2 number & $0.996(0.966-1.027)$ & .80 & & \\
\hline \multicolumn{5}{|l|}{ Adjuvant Chemotherapy } \\
\hline No/yes & $1.388(0.958-2.012)$ & .083 & 1.609 (1.094-2.366) & .016 \\
\hline Cycles completed & $0.956(0.870-1.050)$ & .35 & & \\
\hline \multicolumn{5}{|l|}{ pStage } \\
\hline III/II, I & $2.490(1.735-3.575)$ & $<.001$ & $2.365(1.618-3.458)$ & $<.001$ \\
\hline \multicolumn{5}{|l|}{ Group } \\
\hline Thoracotomy/VATS & $1.162(0.815-1.657)$ & .41 & & \\
\hline
\end{tabular}

conversion rates ranging from $0 \%$ to $22.5 \% .{ }^{15}$ In contrast to the study by Puri and colleagues, ${ }^{16}$ the main cause of conversion was lymph node calcification, which may have been due to the high rate of tuberculosis and inflammation in Chinese people. Meta-analyses showed that the overall complication rates for NSCLC was lower in the VATS group than in the thoracotomy group. ${ }^{2,17}$ In our study, the incidence of postoperative complications was lower in the VATS group than in the thoracotomy group, but statistical significance was not achieved, which may have been due to the small sample size.

Our patients had a longer chest tube duration and longer length of stay than are usually reported because of different indications for removing the tube in Chinese and Western countries. Most Chinese doctors are conservative in treatment and worry about resetting the tube. Thus, they tend to remove the tube later $(<150-200 \mathrm{~mL} / \mathrm{d})$ than in Western hospitals, which leads to a longer length of stay in the hospital. However, we do not think this difference affected our study. We did not compare the exact length of stay in the hospital between Chinese patients and patients in other countries. We compared the 2 groups who adopted the same criteria for removing the chest tube $(<200 \mathrm{~mL} /$ day for at least 2 days). The length of hospital stay and duration of chest tube were similar to those in other studies from China. ${ }^{18}$ In addition, we have adopted western practices of earlier tube removal in recent years, and the length of stay of patients in our department is shorter than before.

There was no difference in performance status or comorbidities between the patients who did and did not receive adjuvant chemotherapy. In accordance with Lee and colleagues' study, ${ }^{19}$ the VATS group trended toward better compliance with adjuvant chemotherapy without a reduced dose, but there was no significant difference. A possible explanation may be lower postoperative pain and lighter psychologic burden with side effects in the VATS group.

The possibility of technique-dependent recurrence rate in VATS lobectomy concerns many surgeons, who consider that factors such as cancer dissemination during manipulation, insufficient surgical margin, or lymph node dissection affect the recurrence rate. The meta-analysis by Zhang and colleagues ${ }^{20}$ revealed that the difference in mean total 
TABLE 7. Univariable and multivariable Cox analyses for overall survival

\begin{tabular}{|c|c|c|c|c|}
\hline & \multicolumn{2}{|c|}{ Univariable analysis } & \multicolumn{2}{|c|}{ Multivariable analysis } \\
\hline & HR $(95 \%$ CI $)$ & $P$ value & HR $(95 \%$ CI $)$ & $P$ value \\
\hline Age & $0.993(0.972-1.013)$ & .49 & & \\
\hline \multicolumn{5}{|l|}{ Sex } \\
\hline Female/male & $1.013(0.649-1.580)$ & .96 & & \\
\hline Tumor size & $0.993(0.885-1.114)$ & .90 & & \\
\hline \multicolumn{5}{|l|}{ Smoking history } \\
\hline No/yes & $0.968(0.658-1.425)$ & .87 & & \\
\hline \multicolumn{5}{|l|}{ Comobility } \\
\hline No/yes & $1.076(0.714-1.623)$ & .73 & & \\
\hline \multicolumn{5}{|l|}{ Histology } \\
\hline Nonadenocarcinoma/adenocarcinoma & $0.958(0.623-1.471)$ & .84 & & \\
\hline FEV1\% & $0.993(0.973-1.013)$ & .47 & & \\
\hline $\mathrm{DLCO} \%$ & $0.991(0.976-1.007)$ & .28 & & \\
\hline \multicolumn{5}{|l|}{ Location } \\
\hline Right/left lobe & $0.791(0.521-1.201)$ & .27 & & \\
\hline Middle or lower/upper lobe & $0.858(0.558-1.318)$ & .48 & & \\
\hline \multicolumn{5}{|l|}{ Lymph node dissection } \\
\hline Stations & $1.003(0.887-1.134)$ & .96 & & \\
\hline Number & $0.995(0.969-1.022)$ & .72 & & \\
\hline N1 stations & $0.888(0.703-1.120)$ & .32 & & \\
\hline N1 number & $0.985(0.928-1.046)$ & .63 & & \\
\hline $\mathrm{N} 2$ stations & $1.049(0.890-1.237)$ & .57 & & \\
\hline $\mathrm{N} 2$ number & $0.996(0.962-1.031)$ & .82 & & \\
\hline \multicolumn{5}{|l|}{ Adjuvant Chemotherapy } \\
\hline No/yes & $1.729(1.140-2.622)$ & .01 & $1.880(1.236-2.858)$ & .003 \\
\hline Cycles completed & $0.892(0.800-0.995)$ & .04 & $1.036(0.824-1.303)$ & .76 \\
\hline \multicolumn{5}{|l|}{ pStage } \\
\hline III/II, I & $1.882(1.244-2.848)$ & .003 & $2.018(1.330-3.062)$ & .001 \\
\hline \multicolumn{5}{|l|}{ Group } \\
\hline Thoracotomy/VATS & $1.075(0.714-1.620)$ & .73 & & \\
\hline
\end{tabular}

lymph node dissection or lymph node sampling numbers between VATS and thoracotomy was not significant in early-stage NSCLC $(P=.14)$. However, systematic lymph node dissection is more complicated and mandates a stricter thorough clearance in locally advanced NSCLC than in the early stage. Lee and colleagues ${ }^{3}$ compared the 2 approaches for all stages of NSCLC and showed that both the number of lymph nodes and the number of lymph node stations removed were less in VATS than in thoracotomy. However, their study reviewed patients over more than 2 decades. Lee and colleagues ${ }^{12}$ showed that a greater number of lymph nodes and nodal stations were sampled in the later period than in the earlier period and indicated a learning curve in VATS nodal dissection, which is similar to our data. Cumulative experience could positively affect the adequacy of lymph node resection. Few studies have reported the incidence of procedure-related tumor dissemination during VATS. Kim and colleagues ${ }^{21}$ compared VATS lobectomy with thoracotomy and did not see an increase in the risk of procedure-related pleural dissemination in patients with VATS. Long-term survival and pattern of recurrence were similar between the 2 groups in 2 recent studies. ${ }^{3,21}$ In comparison, although our study had more patients with advanced-stage disease, there were also no significant differences in both locoregional and distant recurrence. These results may eliminate some apprehension about techniquedependent recurrence rate related to VATS.

Multivariable regression analysis indicated similar DFS and OS with the VATS approach compared with thoracotomy. When the conversions were placed in the thoracotomy group, the VATS group had less blood loss and seemed to have a better survival, although there was no significant difference. In view of a shorter length of hospital stay, likely better compliance with adjuvant chemotherapy, and cumulative experience, we believe VATS showed a suggestion of benefit for patients with locally advanced NSCLC.

\section{Study Limitations}

First, although the data in this study were gathered prospectively, the analysis was performed retrospectively. Second, as in most studies comparing the 2 approaches, it is difficult to eliminate the surgeon's selection bias. 
Complicated tumors (eg, centrally located) may be preferred for thoracotomy. However, because a prospective randomized controlled trial between VATS and open thoracotomy seemed unlikely to be conducted, we believe this propensity analysis minimized bias as much as possible. Third, we did not have data on how many patients received postoperative radiation therapy or targeted therapy, which play important roles in advanced NSCLC and may affect the OS. However, with similar clinical characteristics and number of recurrences between the 2 groups, we considered they might have had the same opportunities to use these therapies, which would not change our results.

\section{CONCLUSIONS}

VATS lobectomy for locally advanced-stage NSCLC can be performed safely with a shorter length of hospital stay and showed similar long-term survival compared with thoracotomy. With continued experience and optimized technique, VATS lobectomy can be performed in the majority of cases without compromising perioperative outcomes and oncologic efficacy.

\section{Conflict of Interest Statement}

Authors have nothing to disclose with regard to commercial support.

The authors thank the hospitals that constitute the database: Jiangsu Cancer Hospital, Shanghai Zhong Shan Hospital, Beijing Friendship Hospital, The Second Xiangya Hospital, Fuzhou Pulmonary Hospital of Fujian, and Bethune First Hospital of Jilin University. The authors also thank Dr Xizhao Sui for the multiinstitutional database maintenance.

\section{References}

1. Detterbeck FC, Mazzone PJ, Naidich DP, Bach PB. Screening for lung cancer: diagnosis and management of lung cancer, 3rd ed: American College of Chest Physicians evidence-based clinical practice guidelines. Chest. 2013; 143(5 Suppl):e78S-92.

2. Yan TD, Black D, Bannon PG, McCaughan BC. Systematic review and metaanalysis of randomized and nonrandomized trials on safety and efficacy of video-assisted thoracic surgery lobectomy for early-stage non-small-cell lung cancer. J Clin Oncol. 2009;27:2553-62.

3. Lee PC, Nasar A, Port JL, Paul S, Stiles B, Chiu YL, et al. Long-term survival after lobectomy for non-small cell lung cancer by video-assisted thoracic surgery versus thoracotomy. Ann Thorac Surg. 2013;96:951-61.

4. Cao C, Zhu ZH, Yan TD, Wang Q, Jiang G, Liu L, et al. Video-assisted thoracic surgery versus open thoracotomy for non-small-cell lung cancer: a propensity score analysis based on a multi-institutional registry. Eur J Cardiothorac Surg. 2013;44:849-54.
5. Hennon MW, Demmy TL. Video-assisted thoracoscopic surgery (VATS) for locally advanced lung cancer. Ann Cardiothorac Surg. 2012;1:37-42.

6. Bu L, Li Y, Yang F, Zhao H, Jiang GC, Li JF, et al. Completely video-assisted thoracoscopic lobectomy versus open lobectomy for non-small cell lung cancer greater than $5 \mathrm{~cm}$ : a retrospective study. Chin Med J (Engl). 2012;125: 434-9.

7. Sullivan R, Alatise OI, Anderson BO, Audisio R, Autier P, Aggarwal A, et al. Global cancer surgery: delivering safe, affordable, and timely cancer surgery. Lancet Oncol. 2015;16:1193-224.

8. Chen K, Li Y, Wang J. VATS vs open lobectomy for stage I or II NSCLC. In: Ferguson MK, ed. Difficult Decisions in Thoracic Surgery: An Evidence-Based Approach. 3rd ed. NY: Springer; 2014:137-52.

9. Zhao H, Bu L, Yang F, Li J, Li Y, Wang J. Video-assisted thoracoscopic surgery lobectomy for lung cancer: the learning curve. World J Surg. 2010;34:2368-72.

10. Li X, Wang J, Ferguson MK. Competence versus mastery: the time course for developing proficiency in video-assisted thoracoscopic lobectomy. J Thorac Cardiovasc Surg. 2014;147:1150-4.

11. Flores RM. Does video-assisted thoracoscopic surgical (VATS) lobectomy really result in fewer complications than thoracotomy? The biases are clear, the role of video-assisted thoracoscopic surgery less so. J Thorac Cardiovasc Surg. 2015; 149:645.

12. Lee PC, Kamel M, Nasar A, Ghaly G, Port JL, Paul S, et al. Lobectomy for nonsmall cell lung cancer by video-assisted thoracic surgery: effects of cumulative institutional experience on adequacy of lymphadenectomy. Ann Thorac Surg. 2016;101:1116-22.

13. Hennon M, Sahai RK, Yendamuri S, Tan W, Demmy TL, Nwogu C. Safety of thoracoscopic lobectomy in locally advanced lung cancer. Ann Surg Oncol. 2011;18:3732-6.

14. Scheel PJ III, Crabtree TD, Bell JM, Frederiksen C, Broderick SR, Krupnick AS, et al. Does surgeon experience affect outcomes in pathologic stage I lung cancer? J Thorac Cardiovasc Surg. 2015;149:998-1004.e1.

15. Rueth NM, Andrade RS. Is VATS lobectomy better: perioperatively, biologically and oncologically? Ann Thorac Surg. 2010;89:S2107-11.

16. Puri V, Patel A, Majumder K, Bell JM, Crabtree TD, Krupnick AS, et al. Intraoperative conversion from video-assisted thoracoscopic surgery lobectomy to open thoracotomy: A study of causes and implications. J Thorac Cardiovasc Surg. 2015;149:55-62.e51.

17. Cao C, Manganas C, Ang SC, Peeceeyen S, Yan TD. Video-assisted thoracic surgery versus open thoracotomy for non-small cell lung cancer: a meta-analysis of propensity score-matched patients. Interact Cardiovasc Thorac Surg. 2013;16: 244-9.

18. Li Y, Wang J. Comparison of clinical outcomes for patients with clinical NO and pathologic N2 non-small cell lung cancer after thoracoscopic lobectomy and open lobectomy: a retrospective analysis of 76 patients. J Surg Oncol. 2012; 106:431-5.

19. Lee JG, Cho BC, Bae MK, Lee CY, Park IK, Kim DJ, et al. Thoracoscopic lobectomy is associated with superior compliance with adjuvant chemotherapy in lung cancer. Ann Thorac Surg. 2011;91:344-8.

20. Zhang Z, Zhang Y, Feng H, Yao Z, Teng J, Wei D, et al. Is video-assisted thoracic surgery lobectomy better than thoracotomy for early-stage non-small-cell lung cancer? A systematic review and meta-analysis. Eur J Cardiothorac Surg. 2013;44:407-14.

21. Kim SH, Kim HK, Choi YS, Kim K, Kim J, Shim YM. Pleural recurrence and long-term survival after thoracotomy and thoracoscopic lobectomy. Ann Thorac Surg. 2013;96:1769-75.

Key Words: lung cancer, video-assisted thoracoscopic lobectomy, locally advanced 
Unmatched Treated

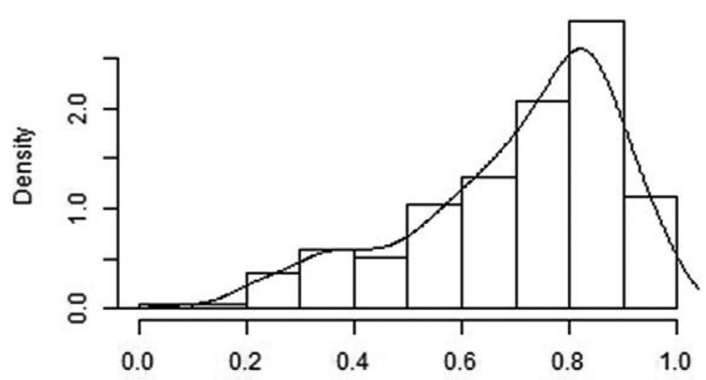

A

Propensity Score

Unmatched Control

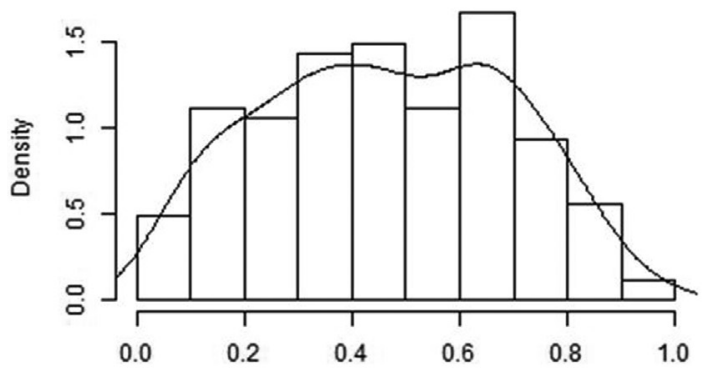

C

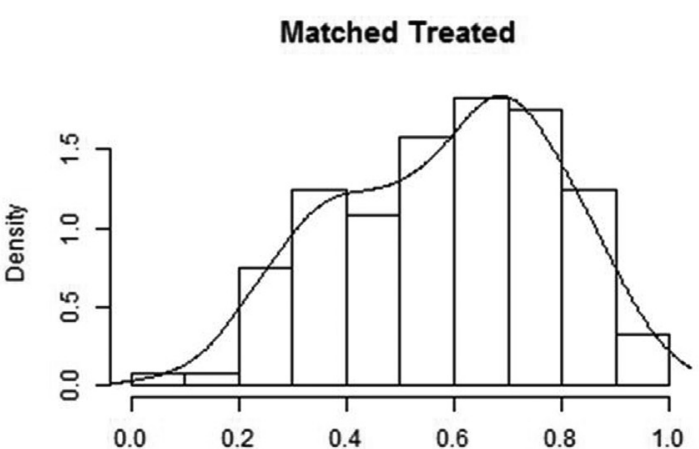

B

Propensity Score

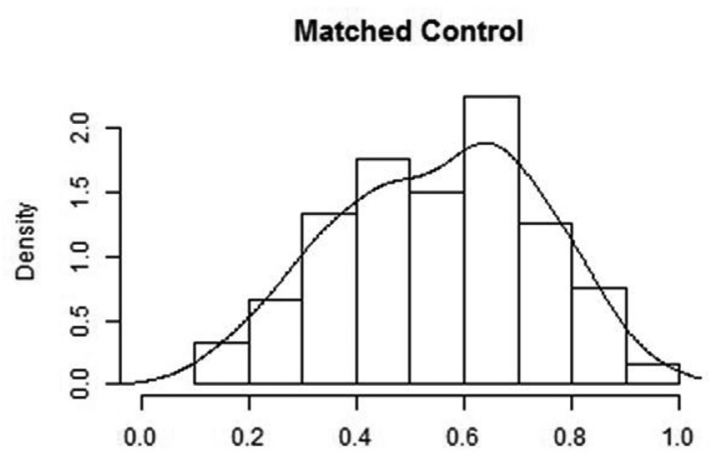

Propensity Score

FIGURE E1. Histogram of propensity scores for patients between VATS and thoracotomy groups (A) unmatched patients who received VATS, (B) matched patients who received VATS, (C) unmatched patients who received thoracotomy, and (D) matched patients who received thoracotomy. Matched groups have similar propensity score distributions. 


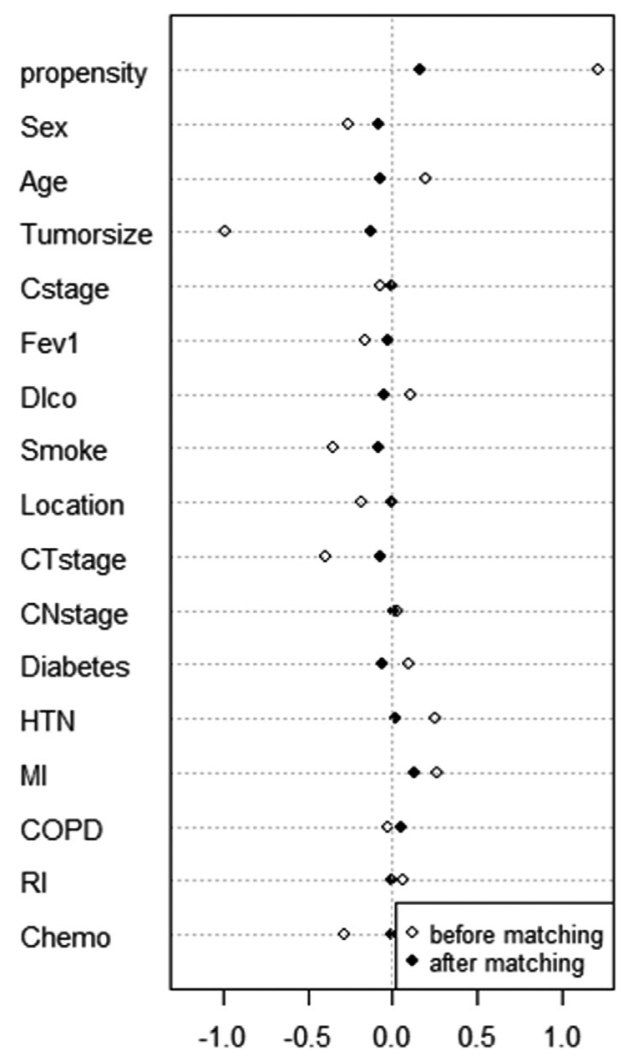

FIGURE E2. Standardized differences of variables between patients who received VATS and patients who received thoracotomy. Hollow diamond symbolizes differences before propensity matching, and black diamond symbolizes differences after propensity matching. Propensity matching effectively reduced heterogeneity among variables between the 2 surgical approaches in comparison. FEV1, Forced expiratory volume in 1 second; $D L C O$, diffusing capacity for carbon monoxide; HTN, hypertension; $M I$, myocardial infarction; $C O P D$, chronic obstructive pulmonary disease; $R I$, renal insufficiency; Chemo, neoadjuvant chemotherapy. 